\title{
DOIS OLHARES SOBRE MASCULINIDADES NO AMBIENTE ESCOLAR: BRASIL E ESPANHA
}

\author{
Carmen GALET ${ }^{1}$ \\ Fernando SEFFNER ${ }^{2}$
}

Resumo: O ambiente escolar e particularmente o espaço da sala de aula são locais de intensa produção de modos de ser homem. O atributo da virilidade circula entre meninos e meninas, com diferentes significados. É possível observar múltiplos questionamentos sobre o conteúdo da masculinidade, cada vez mais posta no plural masculinidades -, a dar conta dos diferentes modos de viver dos meninos. Fruto dessas percepções, nosso entendimento é o de que formar professores e professoras, em termos de gênero, é uma tarefa complexa que requer estar atento ao que ocorre ao nosso redor no dia a dia. A escola é, em parte, um reflexo da sociedade em que vivemos, mas, por outro lado, representa espaço e oportunidade para o aprendizado de mudanças que melhoram o entorno social. São necessários tanto a compreensão acerca da influência das famílias nas questões de gênero quanto o domínio do tema do ponto de vista das ciências humanas. Pensar uma organização produtiva desses debates em sala de aula é bastante desafiador e, ao mesmo tempo, muito necessário. O texto lança dois olhares sobre o tema das masculinidades em sala de aula a partir de duas pesquisas: uma no Brasil e outra na Espanha.

Palavras-chave: Escola. Educação. Gênero. Masculinidade. Identidade.

\section{Do que pensamos sobre educação, dos conceitos e dos métodos de trabalho}

A formação acadêmica que recebem os professores em geral é bastante aceitável se pensamos nos conhecimentos que devem transmitir a alunos e alunas. Nesse sentido, entendemos que os estudantes podem alcançar o domínio das competências instrumentais se os professores os motivarem de modo adequado e se aplicarem metodologias de estudo participativas. Ocorre que a proposta de educação integral que se exige da escola do século XXI contempla outra dimensão, aquela das competências em termos de atitudes e comportamentos que vão além do conhecimento formal. Essas competências têm relação com os processos de socialização que acontecem na infância e no entorno escolar, com o desenvolvimento da identidade pessoal e com os papéis que assumem nas distribuições de poder tanto na sala de aula quanto em outras instâncias da

\footnotetext{
${ }^{1}$ UEX - Universidad de Extremadura. Cáceres- Espanha. 10003 - karmeng@ unex.es

2 UFRGS - Universidade Federal do Rio Grande do Sul. Faculdade de Educação - Pós Graduação em Educação. Porto Alegre - RS - Brasil. 90046-900 - fernandoseffner@ gmail.com
} 
instituição escolar. Para tanto, há que se levar em conta a interação entre a cultura escolar e as culturas juvenis. É no interior desse território que se alojam os aprendizados relativos a gênero e sexualidade, foco deste texto. Temos novas formas de viver as masculinidades e a feminilidade, novos arranjos familiares, códigos morais diversos na sociedade e uma diversidade de posições em relação à sexualidade.

Se a escola efetivamente representa a sociedade, então ela deve, em sintonia com isso, oferecer a seus educandos os valores pelos quais essas novas formas de entender as comunidades em que vivemos estão manifestando-se. Essa é a razão pela qual defendemos que a universidade não apenas deve formar os futuros professores para compreender, assimilar e transmitir o conhecimento acumulado pela humanidade, mas também deve estar consciente de que os educadores são adultos de referência na produção de sociedades mais justas e desejáveis de se viver. Nas mãos dos professores, estão meninos e meninas que serão homens e mulheres de amanhã e que, durante o período escolar, estão formando sua identidade e estruturando seu modo de ver o mundo e de nele atuar. Um dos caminhos que consideramos interessante, do ponto de vista teórico, é trabalhar com a pedagogia da consciência e com a filosofia da realidade. Entendemos estas em uma relação dialética entre a experiência e o trabalho que se desenvolve em sala de aula. Dessa forma, o processo educativo se ocupa não apenas do aprendizado, mas também de como esses aprendizados, convertidos em experiência, dão forma à realidade cotidiana de cada aluno, possibilitando a compreensão de si mesmo e de seu entorno e capacitando-os a refletir sobre seus atos e suas decisões e as respectivas consequências. Nos marcos socioculturais de Brasil e Espanha, há diferenças no trabalho com a identidade de gênero, mas os dois países experimentam convergência ao considerar a necessidade de prover os professores com uma formação docente adequada e ao pensar as questões de gênero e sexualidade como fundamentais para ajudar nos processos identitários das crianças e dos jovens. Nos dois países, são também temas polêmicos, em particular por conta da tensão da escola pública com o universo das religiões.

O acúmulo de pesquisas na área permite perceber que, no Brasil, desenha-se um horizonte em que muitas iniciativas no âmbito da educação escolar apontam para a produção de novas políticas de gênero, lidando diretamente com a proposição de novas trajetórias para meninos e meninas, com inevitáveis atritos com muitos setores sociais, notadamente os grupos religiosos (ARTES; CARVALHO, 2010; CARVALHO, 2009, 2012; GONÇALVES; FRAGA, 2005; PEREIRA; CARVALHO, 2009; REZENDE; 
CARVALHO, 2012; SILVA, 2012). No caso da Espanha, apresentamos a imagem do professor como guia e orientador nesse processo de formação humana, compartilhando a responsabilidade das aprendizagens tanto com a família como com os educandos. A responsabilidade infantil ou adolescente é proporcional à idade e à capacidade de desempenho cognitivo e social. Nesse sentido, para que tenhamos as condições idôneas desse processo durante a aprendizagem, temos que ter um modelo educativo que permita a introjeção no sentido em que utiliza Savater (1982): uma interiorização do sujeito projetado nas relações com os demais. Em outras palavras, faz-se necessário potencializar, em primeiro lugar, a memória para ativar a recordação da experiência, do que foi vivido e aprendido. Em segundo lugar, impulsionar a função simbólica de organização social. Destacamos sua importância no processo educativo, posto que o desenvolvimento positivo e integrado depende da compreensão do mundo, tanto do mundo exterior - tudo aquilo que está no entorno - como do mundo interior, que constitui a vida emocional pessoal. Com essa organização, cada qual constrói a imagem de si mesmo, o que proporciona, de forma individual, um autoconhecimento que é informação recebida do que se vai conhecendo e, ao mesmo tempo, daquilo que se cria como experiência pessoal que forma a identidade. Isso faz com que passado, presente e futuro se articulem no real, mantendo a identidade de cada um. Essa é a consciência que nos permite conhecer a nós e aos outros.

A partir dessa premissa, entendemos que os professores devem programar suas atividades buscando- otimizar as representações mentais, que têm uma relativa importância. Pois que a representação mental há que coincidir com o original, ainda que não em sua totalidade, mas essa construção simbólica deve dialogar com a realidade de forma positiva. Portanto, a imagem mental é uma construção ativa e progressiva que deve tender à otimização da representação. Os professores atuam como guias nessa situação; é uma competência que devem adquirir, já que é considerada imprescindível, pois que, em uma situação coletiva como a da sala de aula, os momentos cotidianos podem ser analisados, aproveitados e programados intencionalmente através do jogo e das dinâmicas para melhorar a qualidade das representações. A pedagogia da consciência obriga, portanto, à reflexão: entender que educar supõe contrair um compromisso com os que aprendem e exige levar a cabo atuações fundamentadas, que encaminham, de forma planejada, a atingir os objetivos da aula.

$\mathrm{Na}$ sequência, apresentamos os achados de pesquisa a partir de duas metodologias diferentes de observação e análises, que se debruçam sobre o que ocorre 
na sala de aula em relação a atravessamentos de gênero no Brasil e na Espanha. Em particular, nosso foco são as manifestações de masculinidade. Uma coleta de dados apoiada na etnografia foi feita em escolas brasileiras de Porto Alegre e proporciona uma descrição rica em detalhes e interações. A outra foi feita em uma escola da Espanha a partir de observação e análise de questionários e entrevistas. São diferentes contextos, diferentes sujeitos, mas há uma forma comum que subjaz as manifestações e que tem a ver com a repartição de poder que a sociedade administra entre os gêneros, o que se relaciona, de forma direta, com a produção das identidades pessoais.

\section{Fricções entre ser bom aluno e ser homem no brasil}

A investigação dos caminhos e estratégias que simultaneamente buscam atender aos objetivos de ser um bom aluno e ser um menino que se encaminha de modo adequado como futuro homem é o propósito de dois projetos de pesquisa. Um deles aproveitou a observação de momentos de docência em escolas públicas para realizar etnografia de sala de aula, colhendo cenas e situações em que os enfrentamentos de gênero e, em particular, as polarizações em torno do eixo "ser bom aluno X comportarse como homem" constituem o tópico em disputa ${ }^{3}$. A segunda estratégia de coleta de dados foi o acompanhamento da dissertação de mestrado de Silva (2012), em que foram feitas entrevistas, grupos focais e observação no território escolar com ênfase nos enfrentamentos de gênero e em suas consequências no aproveitamento escolar. Para a escrita deste artigo, foram aproveitados, dos dois projetos, apenas a descrição de cenas do cotidiano escolar e o resultado de conversas informais com alunos e professores sobre o tema das masculinidades. As entrevistas feitas, bem como a coleta de materiais escritos, são analisadas em outro artigo (SEFFNER; SILVA, 2014). Buscamos cenas no espaço escolar em que os objetos de disputa eram negociações em torno do reconhecimento de ser homem e bom aluno. Já apresentamos as cenas, que foram registradas em diário de campo, acompanhadas de análises em torno dos eixos que escolhemos para estudo. Os nomes e a identificação das escolas foram eliminados, e os

\footnotetext{
${ }^{3}$ Projeto de pesquisa intitulado Ensino Religioso no Interior do Estado Laico: análise e reflexões a partir das escolas públicas de Porto Alegre, vigente entre 2008-2013, que visava analisar as estratégias educacionais e os conteúdos presentes nas aulas de ensino religioso em um conjunto de escolas públicas estaduais do município de Porto Alegre. O campo de trabalho em Porto Alegre foi coordenado por Fernando Seffner, e o projeto fazia interlocução com iniciativa mais ampla de pesquisa, coordenada pela Profa. Dra. Roseli Fischmann da Faculdade de Educação da Universidade de São Paulo (USP). Mais informações sobre o projeto em: <http://lattes.cnpq.br/2541553433398672>. A observação continuada das aulas de ensino religioso revelou muitos momentos em que questões de gênero e, em particular, questões relativas à masculinidade eram a tônica do debate.
} 
eventuais nomes de alunos que aparecem são fictícios em função da preservação do anonimato das fontes.

\section{Cena 1}

Classe noturna da educação de jovens e adultos (EJA), com doze alunos presentes (três senhoras brancas, três moças brancas, três rapazes negros e três adolescentes jovens brancos). A professora que leciona ensino religioso é também a professora de história da classe. Ela propôs atividade de produção de uma linha do tempo da vida escolar de cada um a partir de certos marcadores (escola, turno, conexão com o trabalho, permanência ou não das relações de amizade feitas no ambiente escolar, presença ou não de familiares na mesma escola, interrupções na trajetória etc.). Vale lembrar que a EJA é caracterizada pela presença de alunos com trajetória escolar muito variável e com idades pouco homogêneas. Dessa forma, as linhas do tempo poderiam fornecer marcadores de diferença interessantes para o diálogo, pois a classe tem pelo menos duas gerações distintas de pessoas - as senhoras e os mais jovens -, além da marcação de cor da pele e de gênero. Feitas as linhas de tempo, elas foram afixadas na parede, e cada um foi convidado a falar sobre sua trajetória. A professora foi extremamente respeitosa quanto à questão das reprovações e da evasão escolar, motivos que levam a grande maioria a cursar a educação de jovens e adultos no turno noturno. As três senhoras logo se voluntariaram para falar e descreveram sua vida escolar, explicando o porquê de terem interrompido os estudos (casamento, nascimento de filhos, mudança de cidade, regime de trabalho cansativo etc.). Depois disso, a professora estimulou que os homens falassem para efetuar um contraponto. Os três adolescentes foram, então, para a frente da sala e falaram de suas trajetórias escolares. Ficou evidente que o motivo principal do abandono da escola regular e da inserção na educação de jovens e adultos noturna era uma combinação de necessidade de trabalhar durante o dia com alguns problemas disciplinares enfrentados no turno diurno.

As três mais jovens apresentaram em seguida e, para todas elas, não tinha havido nenhuma reprovação, apenas necessidade de abandono da escola regular por motivo de auxílio nas lides da casa e, em um dos casos, de gravidez. Os três rapazes negros, então, levantaram-se e passaram a comentar suas linhas do tempo. Nitidamente a atividade tomou um rumo mais agitado, pois eles introduziram brincadeira e deboche em relação a suas próprias trajetórias escolares. As brincadeiras oscilaram todas em torno dos problemas disciplinares e das reprovações, que estavam inclusive escritas nas linhas do 
tempo, com a repetição das expressões "rodei de ano", "tomei pau na quinta série", "me reprovaram", “eu incomodei tanto que não me aguentaram”. A algazarra cresceu, e eles passaram a relatar as reprovações e expulsões das escolas por motivos disciplinares ou fraco desempenho escolar como verdadeiros troféus de afirmação de suas masculinidades, em declarações como "eu organizei uma gangue na escola, e eles não me quiseram mais por lá" ou "a diretora mandava bilhete para a minha mãe todos os dias". Ou seja, a exclusão da escola regular passou a ser vista como um elemento de garantia de suas masculinidades, algo de que se orgulhavam. Essa ênfase no relato tomou tais proporções que os três adolescentes que já haviam apresentado suas linhas do tempo passaram a discutir com eles, dizendo que também eles tinham sido reprovados e, em um caso, colocando em dúvida o excessivo número de reprovações e expulsões que os outros estavam apresentando, com a frase "tu terias que ter quarenta anos de idade para ter sido reprovado e expulso das escolas tantas vezes; isso não pode ter acontecido". Claramente a narrativa e o debate ficaram circulando entre os homens, e as mulheres presentes se tornaram espectadoras. Eles questionavam "quem era mais homem", o que estava na contramão de "ser bom aluno", pois "ser bom aluno" havia sido vinculado com as figuras femininas. Estas ou eram as moças jovens que nunca tinham sido reprovadas, ou as senhoras mais velhas que haviam afirmado que gostavam da escola e de estudar, mas que foram forçadas a abandonar a seriação normal por conta de encargos profissionais e familiares, motivo pelo qual as moças jovens também migraram para a educação de jovens e adultos.

A professora teve extrema dificuldade em retomar os termos da atividade e abrir um diálogo sobre os marcadores estabelecidos, fazendo circular a palavra entre a classe. Mesmo assim, os três meninos negros retornavam, sempre que podiam, a afirmações que buscavam enaltecer seu passado de exclusões da escola, visto como clara garantia de sua masculinidade. Isso se expressou em disputas verbais e comentários do tipo: uma das senhoras disse que a diretora da escola não permitia que ela chegasse tarde à aula, e ela não conseguia chegar no horário por conta do trabalho, então teve que desistir naquele ano; um dos rapazes retrucou, então, "se fosse eu, já quebrava tudo", e outro disse "e tu serias expulso", e todos os homens caíram na gargalhada. O continuado tom de deboche e ironias por parte dos meninos, já agora não apenas os três rapazes negros, mas com a inclusão decidida dos três adolescentes brancos, impediu que a atividade pudesse tomar um caráter mais reflexivo acerca das trajetórias escolares. Ficou muito nítido que ser bom aluno era um atributo feminino e que um homem que quisesse ser 
reconhecido como tal deveria enfrentar as regras da instituição, mesmo que isso comprometesse o avanço nos estudos.

\section{Cena 2}

Classe numerosa de alunos e alunas do sexto ano do ensino fundamental crianças em torno de dez anos, turno da manhã, dia claro de verão. Entro na sala, apresento-me e vou sentar ao fundo para observar a aula de ensino religioso. A professora, extremamente enérgica e dinâmica, consegue colocar todos em seus lugares. Ao fazer isso, ela lembra que eles votaram, semanas atrás, um código de conduta para a classe, que está posto em dois cartazes enormes na lateral da sala e que deve ser obedecido. Nessa hora, há muitos risos dos alunos. A professora pergunta o porquê das risadas, e logo a situação se explica. Alguém rabiscou, por cima de um dos cartazes do código de conduta, a expressão "que coisa mais gay” e o nome "José". A professora imediatamente tenta identificar quem fez aquilo, mas logo se dá conta de que isso não será possível. A classe de alunos diz que já faz vários dias que aquilo foi rabiscado ninguém viu, ninguém sabe, revelando uma cumplicidade típica de alunos e alunas no enfrentamento com professores e professoras. Em seguida, dou-me conta de que José, o nome rabiscado, é o de um aluno tímido e reservado, que senta no meio das meninas e que fica visivelmente incomodado com a discussão. A professora diz que ser bom aluno é algo a que todos deveriam esforçar-se para ter futuro na vida e segue por aí na argumentação, evidentemente sem sucesso junto à maioria do público de meninos. Ela manda retirar o cartaz rabiscado da parede e diz que ele será refeito, e logo uma aluna se voluntaria para fazer o novo cartaz. A aula segue.

Na saída, observo com atenção o cartaz rabiscado e o outro que segue na parede e não foi rabiscado. No cartaz rabiscado, estão colocadas as diretrizes que todos devem seguir para ser bons alunos: obedecer à professora; fazer os trabalhos com capricho; sentar direito na cadeira; trazer sempre todo o material escolar organizado; levantar o braço sempre que quiser falar; respeitar os colegas. No cartaz que não foi rabiscado e que segue afixado na parede, estão regras mais de ordem administrativa, como: em caso de ausência no dia das provas, o aluno deverá trazer uma justificativa da família; ao chegar à escola, cada aluno deve avisar às merendeiras se vai ou não querer o lanche na hora do recreio; alunos que não tiverem devolvido os livros na biblioteca no prazo correto levarão um bilhete para os pais e só poderão ingressar na escola quando trouxerem o livro; e outros avisos dessa ordem. Claramente quem rabiscou o cartaz 
escolheu aquele que tratava do que se poderiam chamar de regras de conteúdo moral que afetam as produções de gênero; certamente quem rabiscou deve ter sido algum dos meninos, conforme me contaram duas meninas que perceberam que eu estava lendo o cartaz rabiscado, mas não disseram o nome dos autores, apenas afirmaram "foram os guris". As regras de conduta moral foram tidas como algo "gay" e logo associadas a um dos alunos da classe, "José", tímido, reservado e possivelmente visto pelos demais como afeminado, portanto gay, pouco masculino. Ele e as meninas deveriam, então, obedecer às regras, mas não os meninos, pois as regras impactavam negativamente suas produções enquanto homens.

\section{Conclusões}

As cenas narradas acima permitem perceber a tensão presente nas trajetórias escolares de meninos entre "ser um bom aluno" e "ter a garantia de reconhecimento enquanto homem", sem que recaiam suspeitas de serem femininos ou de serem gays, identidade em geral tomada como uma variação do feminino. É uma tarefa difícil para a escola lidar com essa questão, pois os valores sociais que orientam a produção de masculinidades são vigorosos, e não bastará a escola insistir, de modo isolado, na direção da equidade de gênero - isso precisaria ser feito por outras agências tanto estatais quanto no âmbito da sociedade civil. De toda forma, é desejável que a escola proporcione atividades em que se explicitem as diferenças de gênero, solicitando que meninos e meninas conversem sobre o tema, sobre as expectativas que têm disso e sobre os modos de perceber, de preferência com o apoio de dados estatísticos e de uma estrutura conceitual adequada. Também seria bastante adequado que atividades escolares possibilitassem a experimentação, por meninos e meninas, de novos roteiros de gênero, por vezes invertendo os papéis tradicionais. Já são amplamente conhecidas na literatura educacional experiências em que a escola oportuniza aos meninos momentos para o cuidado de bebês, bem como solicita às meninas o exercício de atividades historicamente masculinas, como carpintaria, jogo de futebol etc. $\mathrm{O}$ relato dessas experiências escolares mostra sempre a adesão mais entusiasmada das meninas ao exercício das atividades masculinas e a resistência dos meninos a ocuparem-se de tarefas de cuidado e outras que são vistas como do campo feminino. Tudo isso tem repercussões nas famílias, que por vezes reclamam de que seus filhos homens estão sendo obrigados ao exercício de atividades vistas como femininas, o que nos faz perceber que essas fronteiras de gênero são de difícil atravessamento social. 


\section{Jogos, brinquedos e construção de masculinidades na Espanha}

A pesquisa na Espanha operou com outras estratégias para a produção de dados. Os instrumentos utilizados foram entrevistas a pais, mães, professores e professoras. Entrevistas estruturadas aos professores e entrevistas abertas semiestruturadas aos pais e às mães. Observação de campo direta, não participante e individual com as crianças, os professores e as professoras na sala de aula. A amostra foi constituída de pais e mães dos 224 alunos e alunas do segundo ciclo de educação infantil, dos quais 107 eram meninos e 117 eram meninas, 10 professores e os 214 alunos e alunas do centro educacional. Os espaços e tempos escolhidos para a observação foram os seguintes: o tempo de jogo dirigido em cada local; o jogo livre dentro da sala de aula; e o tempo de recreio. Ao analisar a tipologia das famílias presentes no estudo, encontramos que cerca de $76 \%$ das crianças pertencem a famílias nucleares, sendo $10 \%$ delas monoparentais e 14\% famílias reconstituídas.

\section{Discussão dos dados}

As reflexões feitas, por razões de eficácia, dão-se a partir das observações individuais de meninos e meninas que formam os grupos da classe, em encontros programados ou casuais, com as famílias e os responsáveis pela educação das crianças. Nesses momentos, compartilhamos observações e ações, que acontecem de forma cotidiana tanto na escola como na família e que se articulam para cumprir com um objetivo comum, a saber, ser autônomo e relacionar-se com os demais a partir de seus desejos e conhecimentos. Outros estudos avaliam que a necessidade de autonomia para as crianças (CHANDLER; CONNELL, 1987; DECI, 1975) e a necessidade de relacionar-se (BAUMEISTER; LEARY, 1995; REIS, 1994) são essenciais para um desenvolvimento adequado e equilibrado - com crescimento e integração com os demais não forçados, feitos de modo espontâneo -, assim como para um desenvolvimento social que leve em conta a noção de uma sociedade de bem-estar para todos.

É evidente que observamos que meninos e meninas, quando se relacionam entre si, partem de uma posição determinada e vão desenvolvendo seus papéis de gênero a partir dela. Esse jogo de vinculações tem lugar nas práticas diárias e é esse exercício que vai permitindo deixar claros os elementos internos e externos que levam a assumir tal ou qual posição. Tal percurso se realiza tanto desde a observação dos demais como 
pelo conhecimento das expectativas sociais, tendo o professor como guia, que orienta condutas, atitudes, ações e jogos com meninos e meninas e que ajuda, de forma consciente ou inconsciente, a configurar tal ou qual posição. Todo esse processo deve dar-se no sentido de permitir um desenvolvimento em que cada educando experimente a liberdade de criar sua própria configuração pessoal em função dos valores que acredita serem os mais adequados a si em estreita sintonia com a noção de bem-estar coletivo. Dessa forma, estamos em sintonia com os estudos de Heider (1958) que nos advertem que é uma condição básica para as pessoas assumir o sentido de sua própria conduta e da dos demais, sendo essa uma dimensão que os professores não podem ignorar. Todos os processos descritos ocorrem enquanto se dão relações de poder, relações de produção de identidades e vínculos emocionais e da ordem da sexualidade. Estão presentes na vida familiar, na vida social, na vida educativa. É, portanto, imperativo conhecer os fatores que intervêm nos processos de formação e decidir que variáveis podem observar-se e, desse modo, facilitar a investigação e a análise da construção social das identidades de gênero.

Outras investigações (DECI; RYAN, 1991, 1985; RYAN, 1995) insistem na necessidade de conhecer e compreender as condições que fomentam ou anulam os potenciais humanos. Elas são de interesse não só porque ajudam na compreensão das causas que provocam certas condutas, mas também porque favorecem o desenho de ambientes escolares e familiares que potencializam o desenvolvimento e as relações, produtos dessas interações sociais, das quais aquelas realizadas na escola têm um papel importante. Na experiência de ordem mais subjetiva e pessoal de como cada pessoa se identifica com seu gênero há um peso específico importante das disposições, modos e valores que a família, como agente de socialização primária, e a escola, como agente secundário, transmitem em seu dia a dia. De modo geral nestes dois ambientes as disposições ensinadas estão fortemente arraigadas em uma ideologia de aceitabilidade das condutas esperadas para ambos os sexos, configurando adesão inconteste a norma em todos os contextos sociais, conforme se discute em Galet e Alzás (2014).

A imagem que se vai formando sobre o sujeito, com suas manifestações de identidade no contexto escolar e no ambiente familiar, está mostrada nos estudos de Connell (1995) como tendo grande impacto na personalidade, em especial nas expressões corporal e cultural. A maneira que cada um elege para expressar essa identidade acontece com muitos marcadores culturais: a roupa que se usa, a forma de comportar-se em determinadas situações, a estruturação de grupos de amigos e amigas, 
os modos de dizer e de falar. São os papéis que se assumem e que manifestam nossa forma de estar no mundo e que estão atravessados pela relação com a norma e desejo de aceitação. Esses modos de ser de cada um variam ao longo do tempo e são negociados, atendendo ao desejo de pertencer a uma cultura, uma classe social, um grupo étnico, entre outros. A família, a escola e os meios de comunicação têm crescentemente assumido o poder de manter e transmitir esses atributos.

Estamos em sintonia com o que afirmam Rosas Vargas e Ríos Manríquez, (2010, p.44)

\begin{abstract}
Não há uma construção identitária independente da simbolização das relações entre os gêneros, sendo que ela se ativa entre um conjunto de práticas sociais que incluem vínculos dos homens com as mulheres e com outros homens. Essas relações se criam e se põem em jogo em zonas de interação que vão desde o mais íntimo e pessoal - como a sexualidade - até o mais amplo das relações sociais e políticas",
\end{abstract}

Como se pode perceber, a masculinidade não supõe apenas a conduta de pessoas isoladas, ela opera como fenômeno social, ou seja, transcende as pessoas para converter-se em uma estrutura ideológica e de poder que sinaliza e oferece modelos a condutas. A masculinidade se produz no encontro constante entre o individual e o cotidiano social, tudo aquilo que a pessoa vive no dia a dia. As vivências acontecem em instituições, que são, portanto, "generificadas", pois portam pedagogias do gênero, ensinam a ser homem e a ser mulher e distribuem poder entre essas duas posições de sujeito. A família é uma dessas instituições, lugar de reprodução de valores e normas sociais e também de criação de novos modos de viver. A escola, por vezes, aparece como espaço que se opõe à família, tomada a família como espaço "natural" e a escola como organização social inventada para transmissão cultural. É na fricção entre essas duas instituições que situamos nossos olhares de pesquisa, tanto no Brasil quanto na Espanha.

Portanto, família e escola podem ser consideradas como locais possíveis tanto para a transmissão dos modos de viver as masculinidades como para o questionamento e a modificação desses modos de viver, em sintonia com as modificações de contexto social e histórico. Podem, então, converter-se em territórios para processos de

\footnotetext{
${ }^{4}$ No original: "No hay una construcción identitaria independiente de la simbolización de las relaciones entre los géneros, sino que la misma se activa entre un conjunto de prácticas sociales que incluyen vínculos de los hombres con las mujeres y con otros hombres. Estas relaciones se crean y se ponen en juego en zonas de interacción que van desde lo más íntimo y personal-como la sexualidad- hasta lo más amplio de las relaciones sociales y políticas." (ROSAS VARGAS; RÍOS MANRÍQUEZ, 2010, p.44)
} 
metamorfose e provocar mudanças nas relações de autoridade e poder. Isso pode acontecer, no caso da escola, em particular quando se eliminam aquelas circunstâncias em que meninos e meninas se veem ameaçados com violências derivadas da forma como manifestam sua identidade de gênero. É propósito da escola a construção de relações mais humanas e mais democráticas entre os gêneros, em sintonia com a natureza do espaço público, que é de negociação e respeito pela diversidade. Bruner (1983) define o jogo desde o aspecto social, assinalando que o papel de representação mental dos conhecimentos cotidianos, em sintonia com os códigos dramáticos e narrativos, está fortemente apoiado nos legados culturais dos povos e nas habilidades instrumentais que se exigem dos indivíduos. É nesse contexto de jogo em que se leva a cabo a análise da realidade, uma vez que assumimos a importância do ato educativo e do jogo como estratégia para tal.

Na comparação entre o comprado pelas famílias e o que foi escolhidos pelas crianças, destacamos que, quando os meninos escolhem cozinhas ou bonecas, seus pais compram, em média, 50\% menos do que nas ocasiões em que as meninas, enquanto os desejos das meninas na escolha de brinquedos se cumprem em cerca de $20 \%$ dos casos. A opção escolhida pelos pais que não querem comprometer-se em oferecer a seus filhos e filhas brinquedos não considerados adequados a seu gênero é optar por brinquedos educativos e desportivos. Dessa maneira, parecem encontrar uma saída neutra ao conflito que se apresenta quando da escolha, considerada não adequada em termos de gênero. Os meninos, no tempo do jogo livre não dirigido, preferem jogar acompanhados, buscam relacionar-se com outros meninos e outras meninas e apenas $14 \%$ deles preferem jogar sozinhos, o que se equilibra com a escolha das meninas, em que $15 \%$ optam por brincar sozinhas. Cerca de $56 \%$ demonstram que ter irmãos ou irmãs maiores e do mesmo sexo influencia na escolha do tipo de jogo, e essa resposta coincide com dados que apresentamos anteriormente.

No geral, os pais e as mães têm consciência de que o jogo é importante porque ajuda a interiorizar condutas e atitudes em relação às questões de gênero. Por outro lado, entendem que as meninas são femininas por natureza. Considera-se que a masculinidade não se supõe tanto como a feminilidade e que os meninos têm que ser treinados a demonstrar sua virilidade de modo constante. Por conta disso, consideram que os meninos que jogam ou brincam com coisas de meninas correm o risco ou o perigo de experimentar certo desvio em suas vidas, o que implica descontrole e certa noção de caos. Observam-se avanços interessantes tanto na família como na escola em relação à 
consciência de respeitar as escolhas de meninos e de meninas em suas manifestações e formas de estar e sentir o processo de criação de suas identidades de gênero. Mas há muito o que realizar em termos educativos nesse sentido. A formação do professorado que educa meninos e meninas há de dispor de uma sólida e coerente formação nesses aspectos, além de ser sensível às manifestações infantis e coerente com suas atuações e observações.

\section{Conclusões gerais}

A formação dos professores e professoras no século XXI tem novas exigências, mais humanas e mais universais, tais como a aquisição de competências em identidade de gênero e uma educação política para a distribuição do poder. Isso deve estar ao lado das tradicionais tarefas da escola em relação à alfabetização científica. É necessário compreender que gênero e sexualidade formam parte das pedagogias culturais, pedagogias difusas que atuam de modo continuado e que requerem novos enfoques e novos programas de trabalho. Essas estratégias pedagógicas escolares devem orientar-se para a construção de um mundo mais plural, mais respeitoso com o diferente, onde o valor do espaço público seja reconhecido. A responsabilidade da educação depende de um regime de compromissos entre as famílias, a escola e as culturas juvenis para a abordagem de um leque variado de temas com compartilhamento de responsabilidades. O objetivo de fazer uma política do bem comum e de integração social que carrega a educação depende da compreensão de mundo, tanto externo quanto interno, de cada um. Isso supõe educar para a construção de uma imagem de si mesmo ativa, progressista e que aposta na relação com os outros. É essencial assumir que a conduta de cada um, tanto quanto a dos demais, está intimamente relacionada com a produção da identidade pessoal e social e que ela guarda estreito vínculo com as expressões de sexualidade e de gênero. Com esse princípio claro, é tarefa de professores e professoras favorecer o desenho de ambientes escolares que apostem no bem-estar pessoal e social, trazendo as famílias para esse diálogo.

As vivências que têm lugar na escola são portadoras de pedagogias de gênero, ensinam formas de ser homem e de ser mulher, de expressar, transmitir, aceitar, rechaçar as diversas formas de viver as masculinidades. Esse é um diálogo que pode ser muito produtivo em sala de aula. Os dados obtidos nas duas investigações mostram que, em geral, há uma preocupação pelos temas de gênero, embora nem pais nem professores tenham claros os modos mais adequados de abordagem. O professorado carece de 
formação para observar, registrar, programar e executar estratégias pedagógicas com respeito à divisão de poder e à equidade de gênero, bem como para lidar com os que se consideram "diferentes" em uma sala de aula. As estratégias de trabalho para gênero e sexualidade contemplam tanto conhecimento científico adequado quanto princípios éticos de educação personalizada que opera no horizonte da equidade de gênero, respeitando desejos e vontades das identidades individuais. A abordagem dos temas deve estar pautada pelos quatro pilares básicos da educação para o século XXI, conforme Delors (1994): aprender a ser, aprender a conhecer, aprender a conviver juntos, aprender a fazer.

\title{
TWO PERSPECTIVES ON MASCULINITIES IN THE SCHOOL ENVIRONMENT: BRAZIL AND SPAIN
}

\begin{abstract}
The school environment and the classroom space are places of intense production of different ways of being a man. We find in school a traffic of different meanings of manhood, attribute that runs between boys and girls. There are multiple questions on the content of masculinity. Increasingly talk about but masculinities in the plural. Train teachers and teachers in gender issues, it is a complex task that requires being attentive to what happens around us on a daily basis. The school is partly a reflection of the society we live in, but on the other is space and opportunity for learning changes that improve the social environment. It is necessary both to understanding the influence of families on gender issues, as the view of the subject domain of the humanities. Think a productive organization of these debates in the classroom is quite challenging, and at the same time very necessary. Text launches two perspectives on the theme of masculinities in the classroom, from two surveys, one in Brazil, one in Spain.
\end{abstract}

Key words: School. Education. Gender. Masculinity. Identity.

\section{REFERÊNCIAS}

ARTES, A.; CARVALHO, M. P. O trabalho como fator determinante da defasagem escolar dos meninos no Brasil: mito ou realidade? Cadernos Pagu, Campinas, v. 34 , p.41-74, 2010.

BAUMEISTER, R. F.; LEARY, M. R. The need to belong: desire for interpersonal attachments as a fundamental human motivation. Psychological Bulletin, Washington, v.117, n. 3, p. 497-529, 1995.

BRUNER, J. S.; WATSON, R. El habla del niño: aprendiendo a usar el lenguaje. Barcelona: Paidós, 1986. 
CARVALHO, M. P. Teses e dissertações sobre gênero e desempenho escolar no Brasil (1993-2007): um estado da arte. Pro-Posições, Campinas, v. 23, p. 220-244, 2012.

CARVALHO, M. P. Gênero, raça e avaliação escolar: um estudo com alfabetizadoras. Cadernos de Pesquisa, São Paulo, v. 39, p. 837-866, 2009.

CHANDLER, C. L.; CONNELL, J. P. Children's intrinsic, extrinsic and internalized motivation: a developmental study of children's reasons for liked and disliked behaviours. British Journal of Developmental Psychology, London, v. 5, n. 4, p.357$365,1987$.

CLATTERBAUGH, K. C. Contemporary perspectives on masculinity: men, women, and politics in modern society. New York: HarperCollins, 1996.

CONNELL, R. Masculinities: the social organization of masculinity. Berkeley: University of California Press, 1995.

DECI, E. L. Intrinsic motivation. New York: Plenum, 1975.

DECI, E. L.; RYAN, R. M. A motivational approach to self: integration in personality. In: DIENSTBIER, R. A. (Org.). Perspectives on motivation: current theory and research in motivation. Lincoln: University of Nebraska Press, 1991. v. 38.

DECI, E. L.; RYAN, R. M. Intrinsic motivation and self-determination in human behavior. New York: Springer Science \& Business Media, 1985.

DELORS, J. La Educación encierra un tesoro: informe de la UNESCO de la comisión internacional para la educación para el siglo XXI. Madrid: Santillana, 1994.

GALET, C.; ALZÁS, T. La Autonomía personal infantil en función del sexo y estilo familiar. In: JIMÉNEZ, A.; GUTIÉRREZ, J.; DÍZ, J. (Org.). Infancia, adolescencia y juventud: aportaciones en un marco conmemorativo. Granada: Editorial GEU, 2015. p.27-36.

GONÇALVES, V. P.; FRAGA, A. B. A Quadra e os cantos: arquitetura de gêneros nas práticas corporais escolares. Lecturas: Educación Fisica y Deportes, Buenos Aires, v.10, n. 87, 2005.

HEIDER, F. The psychology of interpersonal relations. New York: Wiley, 1958.

PEREIRA, F. H.; CARVALHO, M. P. Meninos e meninas num projeto de recuperação paralela. Revista Brasileira de Estudos Pedagógicos, Brasília, v. 90, p. 673-694, 2009.

REIS, H. T. Domains of experience: investigating relationship processes from three perspectives. In: ERBER, R.; GILMOUR, R. (Org.). Theoretical frameworks for personal relationships. Hillsdale: L. Erlbaum Associates, 1994. p. 87-110.

REZENDE, A. B.; CARVALHO, M. P. Meninos negros: múltiplas estratégias para lidar com o fracasso escolar. Sociologia da Educação, Rio de Janeiro, v. 3, n. 5, p. 59-89, 2012. 
ROSAS VARGAS, R.; RÍOS MANRÍQUEZ, M. Diversidad cultural y género. [S.1.: s.n.], 2010. Disponível em: 〈http://www.eumed.net/libros/2010c/747>. Acesso em: 14 nov. 2015.

RYAN, R. M. Psychological needs and the facilitation of integrative processes. Journal of Personality, Farmington, v. 63, n. 3, p. 397-427, 1995.

RYAN, R. M.; CONNELL, J. P. Perceived locus of causality and internalization: examining reasons for acting in two domains. Journal of Personality and Social Psychology, Washington, v. 57, n. 5, p. 749, 1989.

SAVATER, F. Invitación a la ética. Barcelona: Anagrama, 1982.

SEFFNER, F.; SILVA, L. F. Canetas coloridas ou mini-skates? coisas de meninas e coisas de meninos na cultura escolar. Métis: História \& Cultura, Caxias do Sul, v. 13, p.31-60, 2014.

SILVA, L. F. Mind the gap: processos de construção e manutenção das masculinidades e distanciamentos no desempenho escolar de meninos e meninas. 2012. $178 \mathrm{f}$. Dissertação (Mestrado em Educação) - Universidade Federal do Rio Grande do Sul, Porto Alegre, 2012. 